\title{
Unusual variations in the branching pattern of the coeliac trunk and their clinical significance
}

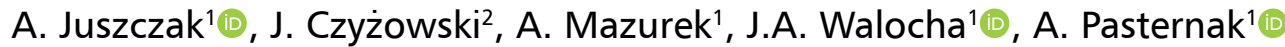 \\ ${ }^{1}$ Department of Anatomy, Jagiellonian University Medical College, Krakow, Poland \\ ${ }^{2}$ Institute of Diagnostic Imaging, J. Diet/ Specialist Hospital, Krakow, Poland
}

[Received: 23 April 2020; Accepted: 7 June 2020]

\begin{abstract}
Background: The anatomical variations of the coeliac trunk are due to developmental changes in the ventral segmental arteries. Multidetector computed tomography (MDCT) has been used to investigate vascular anatomy for scientific and diagnostic purposes. These studies allow for much larger sample sizes than traditional cadaveric studies. The aim of this research was to isolate rare anatomical variants of the coeliac trunk and emphasize their clinical significance.

Materials and methods: A descriptive, retrospective study was carried out on MDCT angiographies performed from January 2020 till March 2020 in Polish patients. Coeliac trunk was studied and normal and anatomical variations were identified.

Results: Out of total 350 patients, hepatogastrosplenic trunk was predominant. However, we observed: coeliaco-mesenteric and hepatogastric trunk type, hepatic artery variations and coeliac axis stenosis with collateral mesenteric circulation.

Conclusions: Rare variations of the coeliac trunk should always be anticipated before radiological and surgical interventions. Knowledge of unusual coeliac trunk anatomy is important in hepatopancreatobiliary surgery, transplantology, and interventional radiology. (Folia Morphol 2021; 80, 2: 283-289)
\end{abstract}

Key words: coeliac trunk, variations, multidetector computed tomography angiography

\section{INTRODUCTION}

The main mesenteric vessels, the coeliac trunk, the superior mesenteric artery (SMA), and the inferior mesenteric artery (IMA) develop from the primitive ventral segmental (splanchnic) branches, which are originally paired vessels. They become the unpaired after the fusion of two dorsal aortae and, next, nourish the gut tube (after yolk sac incorporation) [42]. There is regression of all segmental arteries as development proceeds, except for three of these primitive communications, with only precursors to the three major mesenteric vessels and longitudinal anastomotic vessels remained. The $10^{\text {th }}$ segmental artery gives rise to the coeliac trunk, the $13^{\text {th }}$ segmental artery gives rise to the SMA, and the $21^{\text {st }}$ or $22^{\text {nd }}$ artery gives rise to the IMA. The longitudinal anastomotic vessels between the coeliac trunk and SMA, and between the SMA and IMA disappear [25, 36, 38, 47]. Persistence, incomplete regression, or disappearance of parts of these primitive ventral segmental arteries could give rise to numerous variations of SMA (Fig. 1) [33, 52]. Understanding the different anatomical variations of mesenteric circulation is mandatory in various diagnostic and surgical procedures in the upper abdomen.

Address for correspondence: A. Pasternak, MD, PhD, Department of Anatomy, Jagiellonian University Medical College, ul. Kopernika 12 31-034 Kraków, Poland, tel: +48 1242295 11, fax: +48 1242295 11, e-mail: artur.pasternak@uj.edu.pl

This article is available in open access under Creative Common Attribution-Non-Commercial-No Derivatives 4.0 International (CC BY-NC-ND 4.0) license, allowing to download articles and share them with others as long as they credit the authors and the publisher, but without permission to change them in any way or use them commercially. 


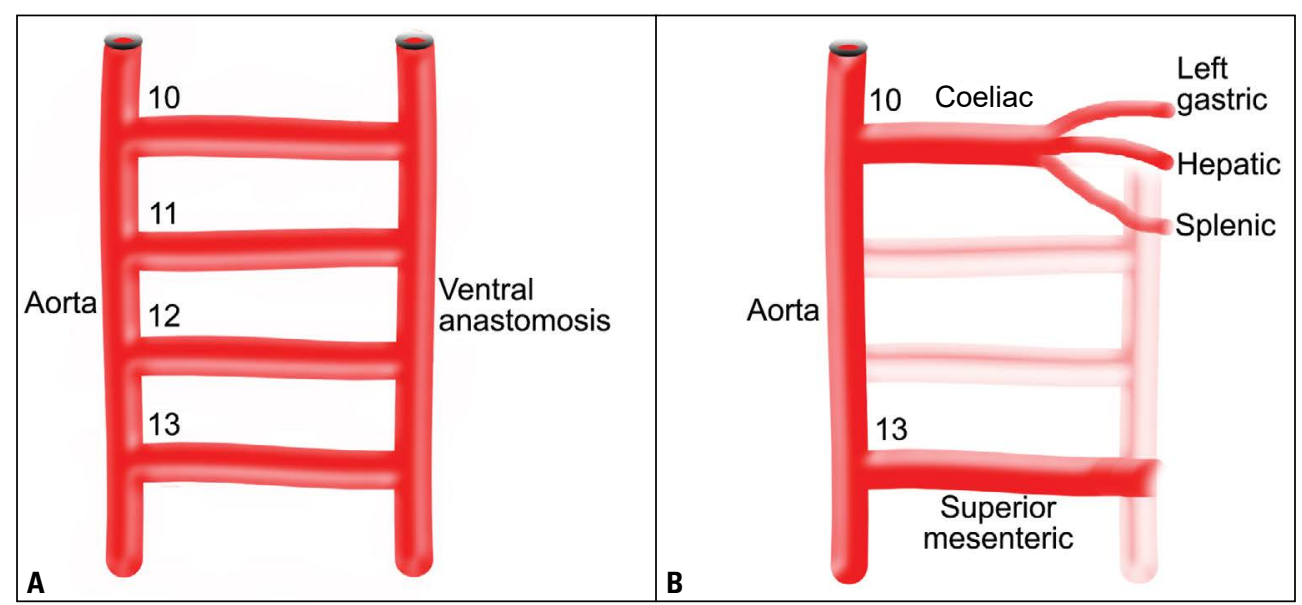

Figure 1. The embryologic origin of the visceral arteries; A. Primitive ventral segmental arteries; B. Normal anatomy demonstrating the coeliac trunk arising from the $10^{\text {th }}$ and superior mesenteric artery from $13^{\text {th }}$ segmental artery, respectively.

Nowadays, evaluation of arteries branching from the abdominal aorta is possible owing to a minimally invasive examination - the multidetector computed tomography angiography (MDCTA). The latest 64-row computed tomography (CT) scanners allow for a very high spatial resolution (up to $0.4 \mathrm{~mm}$ ) and a temporal resolution of only a few seconds. These technical developments have made it possible to acquire detailed knowledge of the abdominal vasculature prior to surgery. This makes the technique indispensable for surgeons, for example, in planning liver transplantation surgery or, more commonly, in fashioning intestinal anastomoses, the success of which is dependent on adequate vascularity [10].

The purpose of this study is to determine arterial branches of the coeliac trunk by using noninvasive imaging technique, MDCTA of the abdominal aorta. Owing to the large number of the analysed examinations, it was possible to isolate rare anatomical variants of coeliac trunk and emphasize their clinical significance.

\section{MATERIALS AND METHODS}

A computer search was performed to identify all the patients who had undergone MDCTA of the abdominal aorta at the Institute of Diagnostic Imaging, J. Dietl Specialist Hospital in Krakow, Poland between January 2020 and March 2020. A total of 350 CT angiographies of abdominal aorta of patients was included in our study and retrospectively reviewed to evaluate the visibility of the coeliac trunk and its branches. All patients met the following inclusion criteria: performance of CT scan in the arterial and venous phase for a variety of clinical indications. Exclusion criteria were the presence of any condition likely to affect normal vascular anatomy, such as prior gastric resection surgery; extended jejunoileal resections; colonic resections; anterior rectal resection; partial pancreaticoduodenectomy; bariatric surgery; liver, pancreas, bowel or multiorgan transplants; and major hepatic resections. Patients were also excluded if they had aneurysmal disease of the splanchnic arteries, severe aortic atherosclerosis, arteritis with possible involvement of the vessels being studied (Kawasaki's disease, polyarteritis nodosa, Takayasu's arteritis, Churg-Strauss syndrome). The study was reviewed and approved by the local Ethics Committee; number 1072.6120.78.2019. The requirement for informed patient consent was waived due to the retrospective nature of the study. CT images were obtained with a 64-channel MDCT scanner (Aquilion 64, Toshiba Medical Systems Corporation, Tokyo, Japan). The contrast medium used was iohexal (Omnipaque 350; GE Healthcare AS, Oslo, Norway), which was administered intravenously by injection pump at a rate of 3-4 mL/s. The dose of the contrast agent was $1 \mathrm{~mL} / \mathrm{kg}$ body weight and the upper limit of dose was set at $100 \mathrm{~mL}$ for every patient.

Image analysis was done on a dedicated Toshiba console equipped with reconstruction software. We used multiplanar reconstructions (MPRs) in the three spatial planes and three-dimensional reconstructions using maximum intensity projection (MIP) and volume rendering (VR). The arterial phase was used to create vascular maps of the coeliac axis including the origin(s) of the hepatic artery and origin of the SMA. Images were interpreted by a radiologist with 15 years of experience in abdominal and vascular imaging. Statistical analysis was done with the Statistical Package for the Social Sciences (SPSS) version 21. 
Table 1. Hepatic artery variations: Michels' classification

\begin{tabular}{lc}
\hline Description & Type \\
\hline Normal anatomy & I \\
Replaced left hepatic artery arising from left gastric artery & II \\
$\begin{array}{l}\text { Replaced right hepatic artery arising from superior mesenteric } \\
\text { artery }\end{array}$ & III \\
$\begin{array}{l}\text { Coexistence of type I and type II } \\
\text { Accessory left hepatic artery arising from left gastric artery }\end{array}$ & IV \\
$\begin{array}{l}\text { Accessory right hepatic artery arising from superior mesenteric } \\
\text { artery }\end{array}$ & VI \\
$\begin{array}{l}\text { Coexistence of type V and type VI } \\
\text { Replaced right hepatic artery and accessory left hepatic artery } \\
\text { or replaced left hepatic artery and accessory right hepatic artery }\end{array}$ & VIII \\
$\begin{array}{l}\text { Common hepatic artery arising from superior mesenteric artery } \\
\text { Common hepatic artery arising from the left gastric artery }\end{array}$ & XX \\
\hline
\end{tabular}

\section{RESULTS}

The study population comprised 198 women (56.6\%) and 152 men (43.4\%) aged between 46 and 88 years (mean age $62.7 \pm 15.3$ ). According to Adachi and Michels' classification different types of normal anatomy or anatomic variants were described (Table 1).

\section{Hepato-gastro-splenic trunk}

This is the classical trifurcation of the coeliac trunk, detected in a total of $340(97.14 \%)$ patients of our series. The typical variant was defined as: the vascular trunk located approximately $1 \mathrm{~cm}$ above the SMA and splitting into 3 branches: left gastric artery (LGA), common hepatic artery (CHA) and splenic artery (SA).

\section{Coeliaco-mesenteric trunk type}

Common origin of the coeliac trunk and of the SMA - the coeliaco-mesenteric trunk (CMT) - was observed in 5 (1.4\%) patients (Fig. 2).

\section{Hepato-gastric trunk type}

Common hepatic and left gastric arteries origin from a common trunk whereas the splenic artery originates from the aorta (1/0, 28\%) (Fig. 3).

\section{Hepatic artery variations}

The following two hepatic arterial variants were observed: the gastro-splenic trunk with the common hepatic artery arising from the SMA (Michels' classification type IX) (Fig. 4) and the gastro-splenic trunk

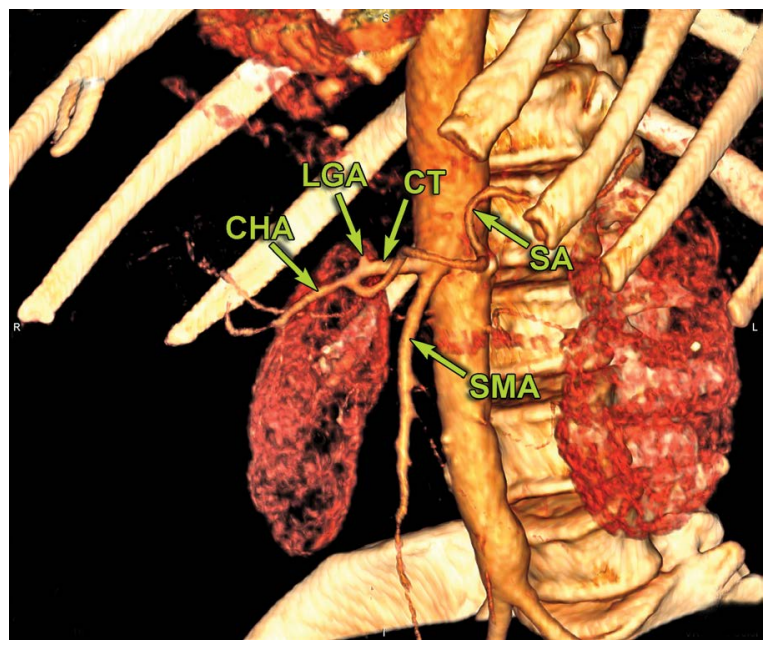

Figure 2. Coeliaco-mesenteric trunk type; $C T$ - coeliac trunk; LGA — left gastric artery; CHA — common hepatic artery; SA — splenic artery; SMA — superior mesenteric artery.

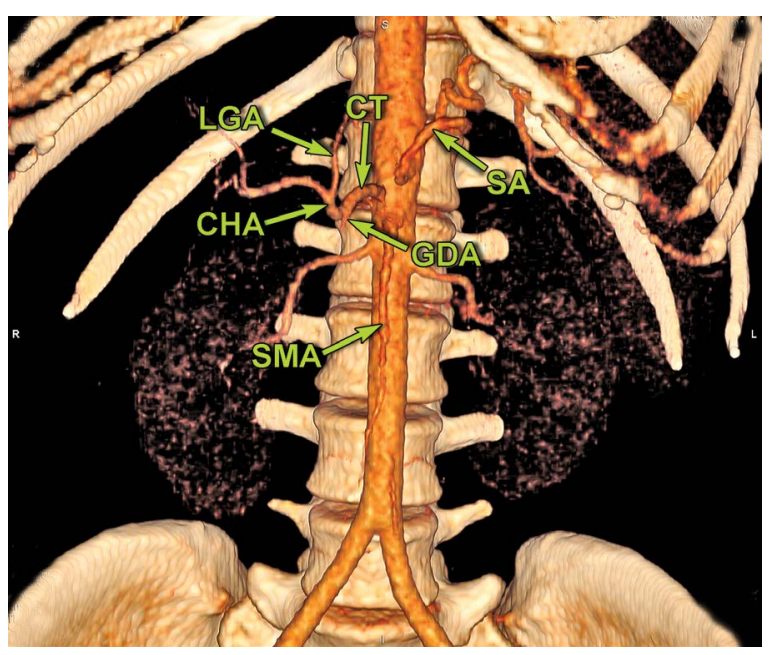

Figure 3. Hepato-gastric trunk type in association with the independent arising of splenic artery (SA); CT — coeliac trunk; CHA common hepatic artery; LGA — left gastric artery; GDA gastroduodenal artery; SMA — superior mesenteric artery.

with the CHA arising independently from aorta and accessory right hepatic artery originating from $\mathrm{CHA}$ (Fig. 5).

\section{Coeliac artery stenosis}

In 1 case there was coeliac artery stenosis resulting in the development of collateral mesenteric circulation, i.e. coeliac artery compression syndrome (CACS) (Fig. 6).

We also observed coeliac artery stenosis with extended collateral mesenteric circulation and SMA originating from aorta slightly above the coeliac trunk (Fig. 7). 


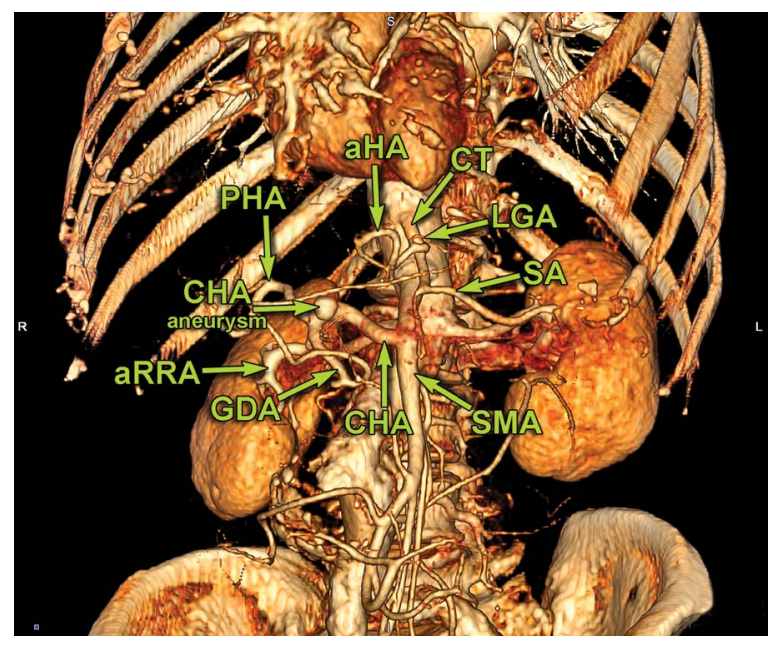

Figure 4. Gastro-splenic trunk type in association with the common hepatic artery (CHA) arising from the superior mesenteric artery; CT — coeliac trunk; LGA — left gastric artery; SA — splenic artery; PHA — proper hepatic artery; GDA — gastroduodenal artery; SMA - superior mesenteric artery; aRRA — accessory right renal artery; CHA aneurysm - common hepatic artery aneurysm; aHA - accessory hepatic artery.

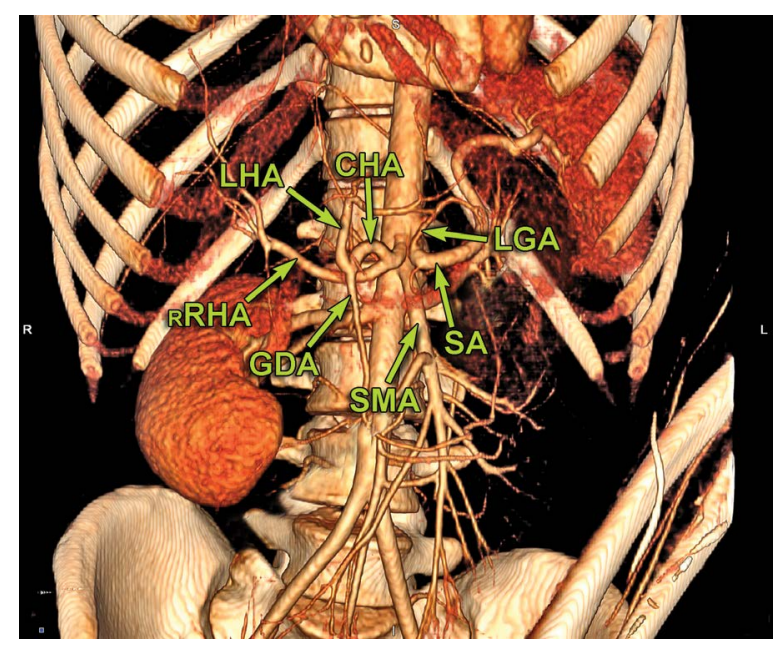

Figure 5. Gastro-splenic trunk in association with the common hepatic artery (CHA) arising independently from aorta and accessory right hepatic artery originating from $\mathrm{CHA}$; $\mathrm{LGA}$ - left gastric artery; SA — splenic artery; SMA — superior mesenteric artery; GDA — gastroduodenal artery; rRHA — replaced right hepatic artery; LHA — left hepatic artery.

In either case the stenosed coeliac trunk corresponded with a hepato-gastro-splenic type in a false configuration.

\section{DISCUSSION}

Most of anatomical reports on the variation of CT are cadaver based studies $[14,22,23,29,35$, 39]. However, in recent years MDCT has been used to investigate vascular anatomy for scientific and

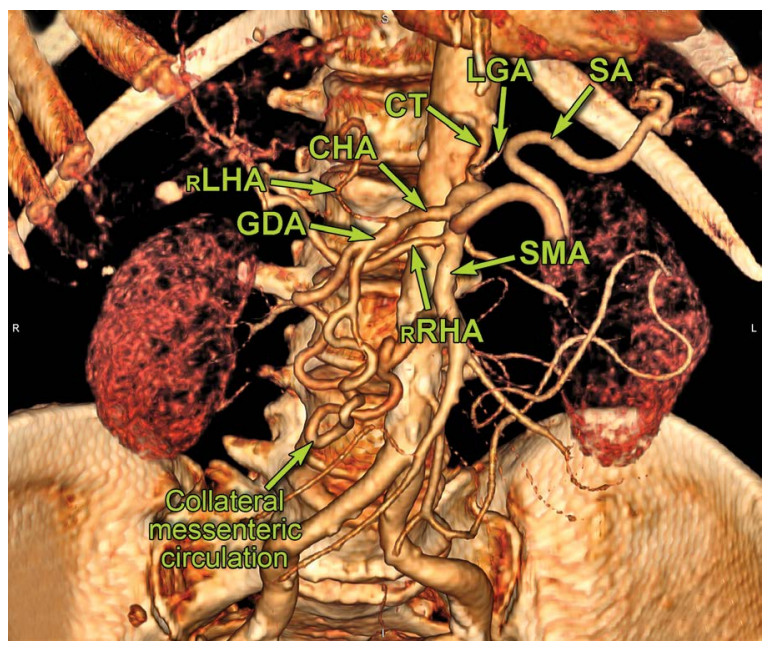

Figure 6. Coeliac artery stenosis resulting in the development of collateral mesenteric circulation; CT — coeliac trunk; LGA — left gastric artery; $\mathrm{CHA}$ - common hepatic artery; SA — splenic artery; SMA — superior mesenteric artery; rRHA — replaced right hepatic artery; GDA — gastroduodenal artery; rLHA — replaced left hepatic artery.

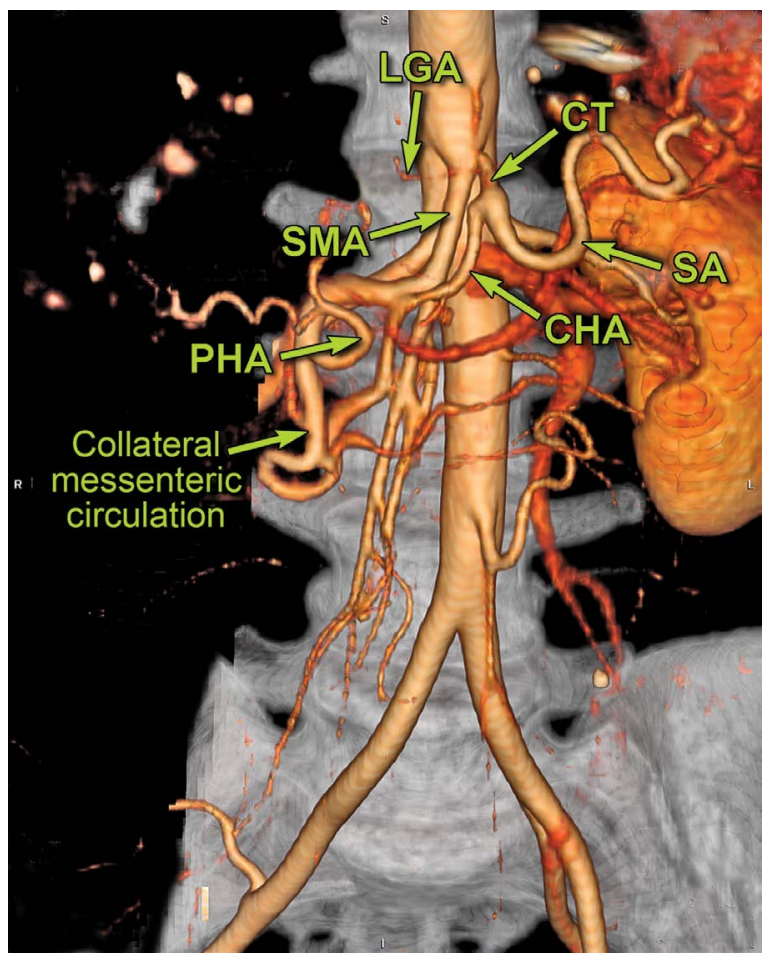

Figure 7. Coeliac artery stenosis with extended collateral mesenteric circulation and superior mesenteric artery (SMA) originating from aorta slightly above the coeliac trunk; CT — coeliac trunk; LGA — left gastric artery; SA — splenic artery; CHA — common hepatic artery; PHA — proper hepatic artery.

diagnostic purposes. These studies allow for much larger sample sizes than traditional cadaveric studies.

The anatomical variations of the CT, SMA and IMA are due to developmental changes in the ventral seg- 
mental arteries [6]. Incomplete fusion or malfusion of the vitelline arteries during the developmental stage may be responsible for the variations of the coeliac trunk.

A CMT occurs when the $10^{\text {th }}$ to $12^{\text {th }}$ vitelline arteries regress and a large portion of the ventral anastomosis persists to connect the coeliac artery and branches to the SMA. The common trunk of the coeliac artery and the SMA is a rare variation and according to the earlier studies, it has been found in $<2 \%$ of patients [34, 42]. A patient with CMT is at risk of mesenteric ischaemia because there lack some of the protective benefits of dual-origin vessels with multiple mutually supporting anastomoses $[2,48,49]$. Anything that compromises the single common trunk arising from the abdominal aorta puts the entire vascular region of the major abdominal viscera at risk of ischaemia [43]. Furthermore, CMT variant could change the SMA angle from the aorta, thus increasing or decreasing the potential for compression of the third portion of the duodenum [43]. Pathologies involving CMT are very rare and include stenosis and aneurysms of the common trunk $[9,24]$. A common CMT thus has a strong potential for development and progression of atherosclerosis along the trunk, which can have severe consequences as it results in ischaemia of the regions supplied by both the coeliac trunk and SMA. Review of the literature reveals several cases of coeliacomesenteric stenosis $[1,4,24,27,30,37,44]$. In these case reports, one patient had an open bypass graft, two had percutaneous angioplasty/stenting, one underwent open surgical endarterectomy with patch-graft angioplasty, one underwent open thrombectomy and one had extra-anatomic right iliac retrograde SMA bypass grafting. The CMT has been reported to be affected by aneurysms, atherosclerotic degeneration, thrombosis, and nutcracker syndrome [28].

The types of hepatic artery variation have been detailed described in Michels' classification [32] and other studies $[8,16,41]$, as well as anatomical monographs [28]. According to Michels' classification [32], the most common variant observed was a replaced right hepatic artery originating from the SMA (Michels III), identified in $9.3 \%$ of patients. It is important to recognize a replaced right hepatic artery when performing pancreaticoduodenectomy and for porta hepatis dissection during hepatic resection. Therefore, if a head or uncinate process pancreatic cancer involves a replaced right hepatic, it precludes the patient from surgical resection. The second most common arterial variant identified was a replaced left hepatic artery (LHA) originating from the left gastric artery, seen in $5.9 \%$ of patients (Michels II). It is important to detect this variant prior to performing left hepatectomy because this vessel must be identified and ligated; the knowledge of this variant facilitates portal dissection because the major arterial branch to the left liver does not need to be found in the porta hepatis. A replaced LHA arising from LGA, may provide a source for collaterals during obstruction of structures in porta hepatis. In addition, it may get damaged during oesophagogastrectomy. This may lead to increased mortality due to hepatic necrosis [15]. Only patients with chronic liver diseases and a reduction of liver reserve functions are most susceptible to ischaemia caused by the replaced LHA ligation; in effect, Huang et al. [17] suggested that the replaced LHA should be preserved in these cases. In order to reduce these ischaemic liver complications, some surgeons suggested a number of techniques for the preservation of the replaced LHA: preservation and peeling of the LGA along with the low tie of the LGA [7]. The LGA branches, directed towards the lesser curvature and the oesophagus, are ligated separately to preserve the LGA and replaced LHA. Next, the LGA is ligated distal to the origin of the replaced accessory LHA. The third most common arterial variant observed was the common hepatic artery arising from the SMA, seen in $3.6 \%$ of cases (Michels IX). We identified this variant in our study. Michels IX variant requires a twisting in anastomosis' order since the artery has to be sutured before the portal vein because of its deeper location posterior to the vein. An accessory LHA originating from the left gastric artery was found (Michels $V$ ). This accessory artery provides an additional source of arterial blood to the left hepatic lobe and may be sutured without compromising the arterial supply to the left hepatic lobe [18]. Knowledge of the variant hepatic arteries is of greatest importance in liver transplantation, since appropriate technical adjustments must be made both in organ procurement and in re-anastomosis in the recipient [12].

Patients with stenosis or occlusion of a single mesenteric artery seldom develop symptoms of chronic mesenteric ischaemia. It is commonly accepted that this is due to the extensive mesenteric arterial collateral circulation. However, mesenteric ischaemia may occur in these patients, for example, in patients with CACS (Dunbar syndrome). This is nonatherosclerotic, respiration-dependent anatomical compression of the coeliac artery by the median arcuate ligament and diaphragmatic crura, which leads to extensive mesenteric collateral circulation. This extrinsic compression 
causes a constellation of symptoms including nausea, vomiting, weight loss, and postprandial epigastric pain [26]. Extensive collaterals are likely to have a compensating function preventing ischaemia in the coeliac artery outflow region [45].

Several studies have demonstrated successful treatment of CACS with coeliac artery release through release of the arcuate ligament $[3,5,13,19,46]$.

Regarding gastrectomy with D2 lymphadenectomy for cancer, it is necessary during surgery to ligate at the root and cut off the left gastric artery, which may affect the hepatic tissue supplied by the replaced/ /accessory LHA deriving from the LGA, thus influencing hepatic function, especially for the replaced right hepatic artery $[11,31,40]$. Therefore, accurate preoperative assessment of whether the abnormal LHA is replaced by the right hepatic artery or accessory right hepatic artery is especially important.

Preoperative knowledge of variant arterial anatomy may reduce extensive exploration during surgery and consequently decrease the risk of vascular damage [51]. According to our current and previous findings, we suggest to apply reconstruction method for evaluation of variations at least in patients who are candidate for mentioned surgical or interventional procedures $[20,21]$. Preoperative MDCTA with three-dimensional reconstruction should be performed before any major surgery on the upper gastrointestinal organs to identify all vascular variations to allow optimal preoperative planning.

\section{CONCLUSIONS}

Rare variations of the coeliac trunk should always be anticipated before radiological and surgical interventions. Knowledge of unusual coeliac trunk anatomy is important in hepatopancreatobiliary surgery, transplantology, and interventional radiology.

\section{REFERENCES}

1. Ailawadi G, Cowles RA, Stanley JC, et al. Common celiacomesenteric trunk: aneurysmal and occlusive disease. J Vasc Surg. 2004; 40(5): 1040-1043, doi: 10.1016/j. jvs.2004.08.028, indexed in Pubmed: 15557926.

2. Alakkam A, Hill RV, Saggio G. Superior mesenteric origin of the proper hepatic artery: embryological and clinical implications. Surg Radiol Anat. 2016; 38(6): 747-750, doi: 10.1007/ s00276-015-1599-0, indexed in Pubmed: 26650050.

3. Aschenbach R, Basche S, Vogl TJ. Compression of the celiac trunk caused by median arcuate ligament in children and adolescent subjects: evaluation with contrast-enhanced MR angiography and comparison with Doppler US evaluation. J Vasc Interv Radiol. 2011; 22(4): 556-561, doi: 10.1016/j. jvir.2010.11.007, indexed in Pubmed: 21316263.
4. Ayers NP, Zacharias SJ, Abu-Fadel MS, et al. Successful use of blunt microdissection catheter in a chronic total occlusion of a celiomesenteric artery. Catheter Cardiovasc Interv. 2007; 69(4): 546-549, doi: 10.1002/ccd.20954, indexed in Pubmed: 17192962.

5. Berard X, Cau J, Déglise S, et al. Laparoscopic surgery for coeliac artery compression syndrome: current management and technical aspects. Eur J Vasc Endovasc Surg. 2012; 43(1): 38-42, doi: 10.1016/j.ejvs.2011.09.023, indexed in Pubmed: 22001148.

6. Cavdar S, Sehirli U, Pekin B. Celiacomesenteric trunk. Clin Anat. 1997; 10(4): 231-234, doi: 10.1002/(SICI)10982353(1997) 10:4<231::AID-CA2>3.0.CO;2-V, indexed in Pubmed: 9213038.

7. Cirocchi R, D'Andrea V, Amato B, et al. Aberrant left hepatic arteries arising from left gastric arteries and their clinical importance. Surgeon. 2020; 18(2): 100-112, doi: 10.1016/j. surge.2019.06.002, indexed in Pubmed: 31337536.

8. Daly J. Long-term hepatic arterial infusion chemotherapy. Arch Surg. 1984; 119(8): 936, doi: 10.1001/archsurg.1984.01390200054013.

9. Detroux M, Anidjar S, Nottin R. Aneurysm of a common celiomesenteric trunk. Ann Vasc Surg. 1998; 12(1): 78-82, doi: 10.1007/s100169900120, indexed in Pubmed: 9452002.

10. Ferrari $R$, De Cecco $C N$, lafrate $F$, et al. Anatomical variations of the coeliac trunk and the mesenteric arteries evaluated with 64-row CT angiography. Radiol Med. 2007; 112(7): 988-998, doi: 10.1007/s11547-007-0200-2, indexed in Pubmed: 17952680.

11. Friesen SR. The significance of the anomalous origin of the left hepatic artery from the left gastric artery in operations upon the stomach and esophagus. Am Surg. 1957; 23(12): 1103-1108, indexed in Pubmed: 13488026.

12. Gielecki J, Zurada A, Sonpal N, et al. The clinical relevance of coeliac trunk variations. Folia Morphol. 2005; 64(3): 123-129, indexed in Pubmed: 16228946.

13. Grotemeyer D, Duran M, Iskandar F, et al. Median arcuate ligament syndrome: vascular surgical therapy and follow-up of 18 patients. Langenbecks Arch Surg. 2009; 394(6): 1085-1092, doi: 10.1007/s00423-009-0509-5, indexed in Pubmed: 19506899.

14. Gurgacz AM, Horbaczewska A, Klimek-Piotrowska W, et al. Variations in hepatic vascularisation: lack of a proper hepatic artery. Two case reports. Folia Morphol. 2011; 70(2): 130-134, indexed in Pubmed: 21630235.

15. Hemming AW, Finley RJ, Evans KG, et al. Esophagogastrectomy and the variant left hepatic artery. Ann Thorac Surg. 1992; 54(1): 166-168, doi: 10.1016/0003-4975(92)91173-7, indexed in Pubmed: 1610235.

16. Hiatt JR, Gabbay J, Busuttil RW. Surgical anatomy of the hepatic arteries in 1000 cases. Ann Surg. 1994; 220(1): 50-52, doi: 10.1097/00000658-199407000-00008, indexed in Pubmed: 8024358.

17. Huang CM, Chen QY, Lin JX, et al. Short-term clinical implications of the accessory left hepatic artery in patients undergoing radical gastrectomy for gastric cancer. PLoS One. 2013; 8(5): e64300, doi: 10.1371/journal.pone.0064300, indexed in Pubmed: 23717589.

18. lezzi R, Cotroneo AR, Giancristofaro D, et al. Multidetector-row $\mathrm{CT}$ angiographic imaging of the celiac trunk: anatomy and normal variants. Surg Radiol Anat. 2008; 30(4): 303-310, doi: 10.1007/s00276-008-0324-7, indexed in Pubmed: 18286222.

19. Jimenez JC, Harlander-Locke M, Dutson EP. Open and laparoscopic treatment of median arcuate ligament syndrome. J Vasc Surg. 2012; 56(3): 869-873, doi: 10.1016/j. jvs.2012.04.057, indexed in Pubmed: 22743019. 
20. Juszczak A, Czyżowski J, Mazurek A, et al. Anatomical variants of celiac trunk in Polish population using multidetector computed tomography angiography. Folia Morphol. 2020 [Epub ahead of print], doi: 10.5603/FM.a2020.0051, indexed in Pubmed: 32394417.

21. Juszczak A, Mazurek A, Walocha JA, et al. Coeliac trunk and its anatomic variations: a cadaveric study. Folia Morphol. 2021; 80(1): 114-121, doi: 10.5603/FM.a2020.0042, indexed in Pubmed: 32301103.

22. Juszczak A, Solewski B, Loukas M, et al. Unusual branching pattern of celiac trunk associated with supernumerary hepatic arteries and abnormal adrenal venous drainage case study and review of the literature. Folia Med Cracov. 2017; 57(3): 29-36, indexed in Pubmed: 29263452.

23. Kahn $\mathrm{Cl}$, MacNeil M, Fanola $\mathrm{C}$, et al. Complex arterial patterning in an anatomical donor. Trans Res Anat. 2018(12): 11-19.

24. Kalra M, Panneton JM, Hofer JM, et al. Aneurysm and stenosis of the celiomesenteric trunk: a rare anomaly. J Vasc Surg. 2003; 37(3): 679-682, doi: 10.1067/mva.2003.37, indexed in Pubmed: 12618711.

25. Katagiri H, Ichimura K, Sakai TA. case of celiacomesenteric trunk with some other arterial anomalies in a Japanese woman. Anat Sci Int. 2007; 82: 53-58.

26. Kim EN, Lamb K, Relles D, et al. Median arcuate ligament syndrome-review of this rare disease. JAMA Surg. 2016; 151(5): 471-477, doi: 10.1001/jamasurg.2016.0002, indexed in Pubmed: 26934394.

27. Lagoutte N, Facy O, Guiu B, et al. Celiacomesenteric trunk: a variation that must be known before aortic surgery. Clin Pract. 2011; 1(3): e69, doi: 10.4081/cp.2011.e69, indexed in Pubmed: 24765330.

28. Lanz VT, Wachsmuth W. Lanz/Wachsmuth Practical Anatomy. Springer-Verlag, Berlin 2003.

29. Lee JK, Kang SR, Kim J, et al. A rare variation of the incomplete coeliac trunk. Folia Morphol. 2016; 75(1): 122-124, doi: 10.5603/FM.a2015.0074, indexed in Pubmed: 26365854.

30. Lovisetto F, Finocchiaro De Lorenzi G, Stancampiano P, et al. Thrombosis of celiacomesenteric trunk: report of a case. World J Gastroenterol. 2012; 18(29): 3917-3920, doi: 10.3748/wjg.v18.i29.3917, indexed in Pubmed: 22876046.

31. Lurie AS. The significance of the variant left accessory hepatic artery in surgery for proximal gastric cancer. Arch Surg. 1987; 122: 725-728.

32. Michels NA. Newer anatomy of the liver and its variant blood supply and collateral circulation. Am J Surg. 1966; 112(3): 337-347, doi: 10.1016/0002-9610(66)90201-7, indexed in Pubmed: 5917302.

33. Nantiskarn C, Kiat A. Aberrant branches of the superior mesenteric artery detected by MDCT angiography of abdominal aorta. Asian Biomedicine. 2012; 6(2): 219-226.

34. Nebesar RA, Kornblith PL, Pollard JJ, Michels NA. Celiac and superior mesenteric arteries: a correlation of angiograms with dissections. Little, Brown, Boston 1969.

35. Olewnik $Ł$, Wysiadecki G, Polguj M, et al. Types of coeliac trunk branching including accessory hepatic arteries: a new point of view based on cadaveric study. Folia Morphol. 2017; 76(4): 660-667, doi: 10.5603/FM.a2017.0053, indexed in Pubmed: 28612916.

36. Oran I, Yesildag A, Memis A. Aortic origin of right hepatic artery and superior mesenteric origin of splenic artery: two rare variations demonstrated angiographically. Surg Radiol Anat. 2001; 23(5): 349-352, doi: 10.1007/s00276001-0349-7, indexed in Pubmed: 11824137.

37. Ratra A, Campbell S. Recurrent mesenteric ischemia from celiomesenteric trunk stenosis. Cureus. 2018; 10(6): e2751, doi: 10.7759/cureus.2751, indexed in Pubmed: 30094108.
38. Rosenblum JD, Boyle CM, Schwartz LB. The mesenteric circulation. Anatomy and physiology. Surg Clin North Am. 1997; 77(2): 289-306, doi: 10.1016/s00396109(05)70549-1, indexed in Pubmed: 9146713.

39. Selvaraj L, Sundaramurthi I. Study of normal branching pattern of the coeliac trunk and its variations using $C T$ angiography. J Clin Diagn Res. 2015; 9(9): AC01-AC04, doi: 10.7860/ JCDR/2015/12593.6523, indexed in Pubmed: 26500893.

40. Shinohara T, Ohyama S, Muto T, et al. The significance of the aberrant left hepatic artery arising from the left gastric artery at curative gastrectomy for gastric cancer. Eur J Surg Oncol. 2007; 33(8): 967-971, doi: 10.1016/j. ejso.2007.02.030, indexed in Pubmed: 17418995.

41. Suzuki T, Nakayasu A, Kawabe K, et al. Surgical significance of anatomic variations of the hepatic artery. Am J Surg. 1971; 122(4): 505-512, doi: 10.1016/00029610(71)90476-4, indexed in Pubmed: 5098656.

42. Tandler J. über die Varietäten der Arteria coeliaca und deren Entwickelung. Beiträge und Referate zur Anatomie und Entwickelungsgeschichte. Anat Embryol. 1904; 25(2): 473-500, doi: 10.1007/bf02300762.

43. Tang W, Shi J, Kuang LQ, et al. Celiomesenteric trunk: New classification based on multidetector computed tomography angiographic findings and probable embryological mechanisms. World J Clin Cases. 2019; 7(23): 3980-3989, doi: 10.12998/wjcc.v7.i23.3980, indexed in Pubmed: 31832400.

44. Tasleem SH, Younas F, Syed FA, et al. Endovascular repair of common celiomesenteric trunk stenosis. Vasa. 2010; 39(4): 341-343, doi: 10.1024/0301-1526/a000059, indexed in Pubmed: 21104624.

45. van Petersen AS, Kolkman JJ, Gerrits DG, et al. Dutch Mesenteric Ischemia Study Group. Clinical significance of mesenteric arterial collateral circulation in patients with celiac artery compression syndrome. J Vasc Surg. 2017; 65(5): 1366-1374, doi: 10.1016/j.jvs.2016.11.052, indexed in Pubmed: 28259570.

46. van Petersen AS, Vriens BH, Huisman AdB, et al. Retroperitoneal endoscopic release in the management of celiac artery compression syndrome. J Vasc Surg. 2009; 50(1): 140-147, doi: 10.1016/j.jvs.2008.12.077, indexed in Pubmed: 19563962.

47. Walker TG. Mesenteric vasculature and collateral pathways. Semin Intervent Radiol. 2009; 26(3): 167-174, doi: 10.1055/s-0029-1225663, indexed in Pubmed: 21326561.

48. Wang Yi, Chen $\mathrm{P}$, Shen N, et al. Celiomesenteric trunk with concurrent aneurysm: report of a case. Surg Today. 2010; 40(5): 477-481, doi: 10.1007/s00595-009-4164-9, indexed in Pubmed: 20425555.

49. Wang Yi, Cheng C, Wang Lu, et al. Anatomical variations in the origins of the celiac axis and the superior mesenteric artery: MDCT angiographic findings and their probable embryological mechanisms. Eur Radiol. 2014; 24(8): 1777-1784, doi: 10.1007/s00330-014-3215-9, indexed in Pubmed: 24859597.

50. Whitley $A$, Oliverius $M$, Kocián $P$, et al. Variations of the celiac trunk investigated by multidetector computed tomography: Systematic review and meta-analysis with clinical correlations. Clin Anat. 2020; 33(8): 1249-1262, doi: 10.1002/ca.23576, indexed in Pubmed: 32012339.

51. Winston CB, Lee NA, Jarnagin WR, et al. CT angiography for delineation of celiac and superior mesenteric artery variants in patients undergoing hepatobiliary and pancreatic surgery. Am J Roentgenol. 2007; 189(1): W13-W19, doi: 10.2214/AJR.04.1374, indexed in Pubmed: 17579128.

52. Yi SQ, Li J, Terayama H, et al. A rare case of inferior mesenteric artery arising from the superior mesenteric artery, with a review of the review of the literature. Surg Radiol Anat. 2008; 30(2): 159-165, doi: 10.1007/s00276-0070298-x, indexed in Pubmed: 18189117. 